\title{
XV Encontro Nacional de Tecnologia do Ambiente Construído \\ O EFEITO DA AMPLITUDE DIÁRIA DA TEMPERATURA DO AR EXTERIOR E DO RESFRIAMENTO NOTURNO NA INÉRCIA TÉRMICA DE HABITAÇÃO
}

\section{CASTRO, Guilherme Molnar (1); BRITO, Adriana Camargo de (2); AKUTSU, Maria (3); VITTORINO, Fúlvio (4)}

(1) IPT, e-mail: gmolnar@ipt.br (2) IPT, e-mail: adrianab@ipt.br (3) IPT, e-mail: akutsuma@ipt.br (4) IPT, e-mail: fulviov@ipt.br

\begin{abstract}
Resumo
Nesse estudo foram realizadas análises para verificar a influência das características térmicas das paredes, da amplitude diária de temperatura do ar externo e da ventilação dos ambientes no período noturno na inércia térmica dos ambientes. Foram feitas simulações do comportamento térmico de uma habitação térrea de interesse social com o programa EnergyPlus, variando-se a espessura das paredes de 5 a $30 \mathrm{~cm}$, a amplitude diária da temperatura do ar externo de 9,2 a $12,2{ }^{\circ} \mathrm{C}$ e a condição de ventilação noturna, considerando-se ventilação neste período de 1 e 5 renovações do volume de ar do ambiente por hora. Os resultados mostraram efeitos mais significativos com a variação das espessuras das paredes de 5 até 15 cm na inércia térmica da edificação.
\end{abstract}

Palavras-chave: comportamento térmico, simulação, habitação, inércia térmica.

\begin{abstract}
In this paper was analyzed the thermal behavior of a dwelling in order to verify the effect of the thermal characteristics of the walls, the daily range of outdoor air temperature and the night ventilation in the thermal inertia of the building. It were performed computational simulations using the software EnergyPlus, considering various wall thickness from 5 to $30 \mathrm{~cm}$, the daily amplitude of the external air temperature from 9.2 to $12.2^{\circ} \mathrm{C}$ and night ventilation, ventilation from 1 to 5 air changers per hour. The results show significant effects for wall thicknesses of 5 to $15 \mathrm{~cm}$ on the thermal inertia of the building.
\end{abstract}

Keywords: thermal behavior, simulation, dwelling, thermal inertia.

\section{INTRODUÇÃO}

A inércia térmica é uma técnica passiva de climatização de ambientes ventilados naturalmente, utilizada historicamente em locais com alta amplitude diária da temperatura do ar. Edifícios com alta inércia térmica são, geralmente, constituídos por materiais como pedra ou terra, com componentes maciços de grande espessura, o que lhes confere também alta capacidade térmica. Edifícios com estas características proporcionam condições térmicas mais amenas, em comparação com aquelas encontradas no seu exterior.

Em um ambiente, a inércia térmica pode ser caracterizada por um parâmetro denominado fator de amortecimento, dado pela razão entre a amplitude do ar interior e a amplitude do ar exterior. Quanto menor for o valor deste fator, maior é a inércia térmica do recinto. 
Há diversas variáveis que são determinantes da inércia térmica de ambientes, como por exemplo, o projeto arquitetônico da edificação, a orientação solar das fachadas e o sombreamento das aberturas como estudado por vários autores (VERBEKE, 2010; GREGORY et al., 2008; CHAN et al., 1999). Dentre estas variáveis, destacam-se as características térmicas da envoltória, a ventilação dos ambientes e as condições climáticas do local como alguns dos principais aspectos a se considerar em um projeto arquitetônico, tendo como objetivo utilizar a inércia térmica para se proporcionar condições térmicas adequadas aos usuários.

Neste artigo tem-se como objetivo verificar o efeito da amplitude diária da temperatura do ar exterior e do resfriamento noturno na inércia térmica de uma habitação de interesse social no período de verão da cidade de São Paulo - SP.

\section{MÉTODO}

Foi analisada a resposta térmica de uma habitação típica de interesse social (Figura 1) com variações nas características das paredes externas, nas condições de ventilação dos ambientes e na amplitude diária da temperatura do ar exterior, conforme descrito nos itens 2.1 a 2.3 , respectivamente.

\section{Figura 1 - Projeto da habitação analisada}
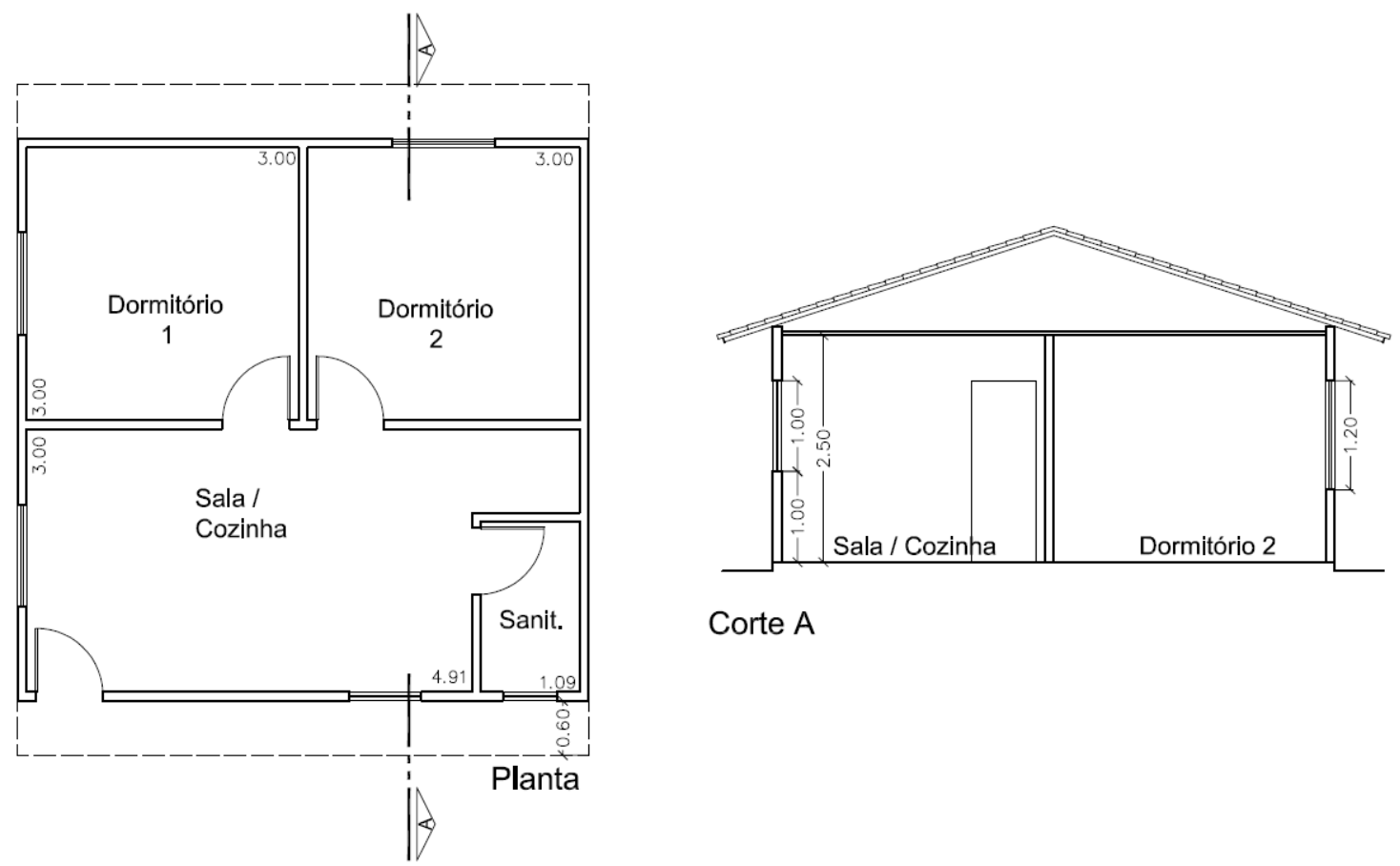

Corte A

Fonte: Adaptado de CDHU (1997).

A resposta térmica da habitação foi obtida por meio de simulações computacionais com base nos procedimentos indicados na norma ABNT NBR 15575 Edificações Habitacionais - Desempenho (ABNT, 2013). Foi utilizado o programa EnergyPlus (USDOE, 2013), que considera condições transientes de trocas de calor.

Foram obtidos os valores horários das temperaturas do ar exterior e no interior de todos os recintos da habitação e calculados os valores do fator de amortecimento - razão entre as amplitudes diárias da temperatura do ar interior e do ar exterior. A partir destes dados verificou-se o efeito das variáveis consideradas na inércia térmica da habitação. 
Observa-se que foram analisados somente os resultados obtidos para o "Dormitório 1", que possui condições térmicas mais críticas de acordo com a referida norma, com a parede que contém a janela voltada à direção Oeste e outra parede voltada à direção Norte.

\subsection{Sistema construtivo da habitação e variações analisadas}

A edificação é composta por paredes em painéis maciços de concreto convencional com variações na sua espessura de 5 a $30 \mathrm{~cm}$ e cobertura com laje do mesmo material, com $10 \mathrm{~cm}$ de espessura e telhado em telhas cerâmicas.

Foram utilizadas cores médias no acabamento externo das paredes, com absortância térmica à radiação solar igual a 0,5. O acabamento externo das telhas da cobertura tem cores escuras, com absortância à radiação solar de 0,7. As características térmicas dos materiais utilizados na habitação são apresentadas na Tabela 1 e os valores da capacidade térmica e da transmitância térmica das paredes, na Tabela 2.

Tabela 1 - Propriedades térmicas dos materiais utilizados na habitação analisada

(ABNT, 2005)

\begin{tabular}{|c|c|c|c|}
\hline Material & $\begin{array}{c}\text { Condutividade } \\
\text { térmica } \\
(\mathbf{W} / \mathbf{m} \cdot \mathbf{K})\end{array}$ & $\begin{array}{c}\text { Massa específica } \\
\left(\mathbf{k g} / \mathbf{m}^{\mathbf{3}}\right)\end{array}$ & $\begin{array}{c}\text { Calor específico } \\
(\mathbf{k J} / \mathbf{k g} \cdot \mathbf{K})\end{array}$ \\
\hline Cerâmica & 0,90 & 1600 & 0,92 \\
\hline Concreto & 1,75 & 2400 & 1,00 \\
\hline
\end{tabular}

Tabela 2 - Capacidade térmica e resistência térmica das paredes segundo sua espessura

\begin{tabular}{|c|c|c|}
\hline Espessura da parede $(\mathbf{c m})$ & $\mathbf{C}\left(\mathbf{k J} / \mathbf{m}^{\mathbf{2}} \mathbf{K}\right)$ & $\mathbf{R}\left(\mathbf{m}^{\mathbf{2}} \mathbf{K} / \mathbf{W}\right)$ \\
\hline 5 & 120 & 0.20 \\
\hline 10 & 240 & 0.23 \\
\hline 15 & 360 & 0.26 \\
\hline 20 & 480 & 0.29 \\
\hline 25 & 600 & 0.32 \\
\hline 30 & 720 & 0.35 \\
\hline
\end{tabular}

\subsection{Condições de ventilação da habitação}

Os ambientes da habitação foram simulados em duas situações:

a) Com trocas de ar entre os ambientes interior e exterior a uma taxa constante de uma renovação do volume de ar do ambiente por hora (1 Ren/h) durante as vinte e quatro horas do dia;

b) Renovação do volume de ar do ambiente interno a uma taxa de cinco renovações do volume de ar do ambiente ( $5 \mathrm{Ren} / \mathrm{h}$ ), durante o período noturno, das $21 \mathrm{~h}$ às $9 \mathrm{~h}$.

\subsection{Condições climáticas e variações analisadas}

Foi considerado um dia típico de verão da cidade de São Paulo - SP, representando a Zona Bioclimática Brasileira 3 (ABNT, 2005). Os dados climáticos desta cidade são indicados na Tabela 3. 
Tabela 3 - Dados climáticos do dia típico de verão da cidade de São Paulo

\begin{tabular}{|c|c|c|c|c|c|c|c|}
\hline Cidade & Período & $\begin{array}{c}\text { Temp. } \\
\text { máxima } \\
\text { do ar } \\
\left({ }^{\circ} \mathbf{C}\right)\end{array}$ & $\begin{array}{c}\text { Amplitude } \\
\text { diária da } \\
\text { temp. do } \\
\text { ar }\left({ }^{\mathbf{O}} \mathbf{C}\right)\end{array}$ & $\begin{array}{c}\text { Temp. } \\
\text { de } \\
\text { bulbo } \\
\text { úmido } \\
\left({ }^{\mathbf{0}} \mathbf{C}\right)\end{array}$ & $\begin{array}{c}\text { Radiação } \\
\text { solar } \\
\text { global } \\
\text { plano } \\
\text { horizontal } \\
\left(\mathbf{W} / \mathbf{m}^{2}\right)\end{array}$ & $\begin{array}{c}\text { Radiação } \\
\text { solar } \\
\text { incidente } \\
\text { na fachada } \\
\text { oeste } \\
\left(\mathbf{W} / \mathbf{m}^{2}\right)\end{array}$ & $\begin{array}{c}\text { Radiação } \\
\text { solar } \\
\text { incidente } \\
\text { na fachada } \\
\text { norte } \\
\left(\mathbf{W} / \mathbf{m}^{2}\right)\end{array}$ \\
\hline $\begin{array}{c}\text { São } \\
\text { Paulo }\end{array}$ & Verão & 31,9 & 9,2 & 21,3 & 5180 & 2802 & 1267 \\
\hline
\end{tabular}

Fonte: ABNT (2013).

Efetuaram-se variações no valor da amplitude diária da temperatura do ar exterior de 9,2 a $12,2{ }^{\circ} \mathrm{C}$, com o propósito de se obter informações sobre o seu efeito na inércia térmica da habitação.

\section{RESULTADOS}

\subsection{Efeito das características térmicas da envoltória na inércia térmica do ambiente}

À medida que se aumenta a espessura das paredes, mais atenuada é a amplitude diária da temperatura do ar interior. Esta atenuação é mais significativa nos casos de paredes com espessura acima de $15 \mathrm{~cm}$. Isso pode ser observado na Figura 2, que apresenta os perfis diários das temperaturas do ar exterior e interior para varias espessuras de paredes, considerando a amplitude diária da temperatura do ar exterior igual a $9,2{ }^{\circ} \mathrm{C}$ e ambientes sem ventilação noturna.

Figura 2 - Temperatura do ar exterior e interior para várias espessuras de paredes, com amplitude térmica diária de $9,2{ }^{\circ} \mathrm{C}$ e ambientes sem ventilação noturna

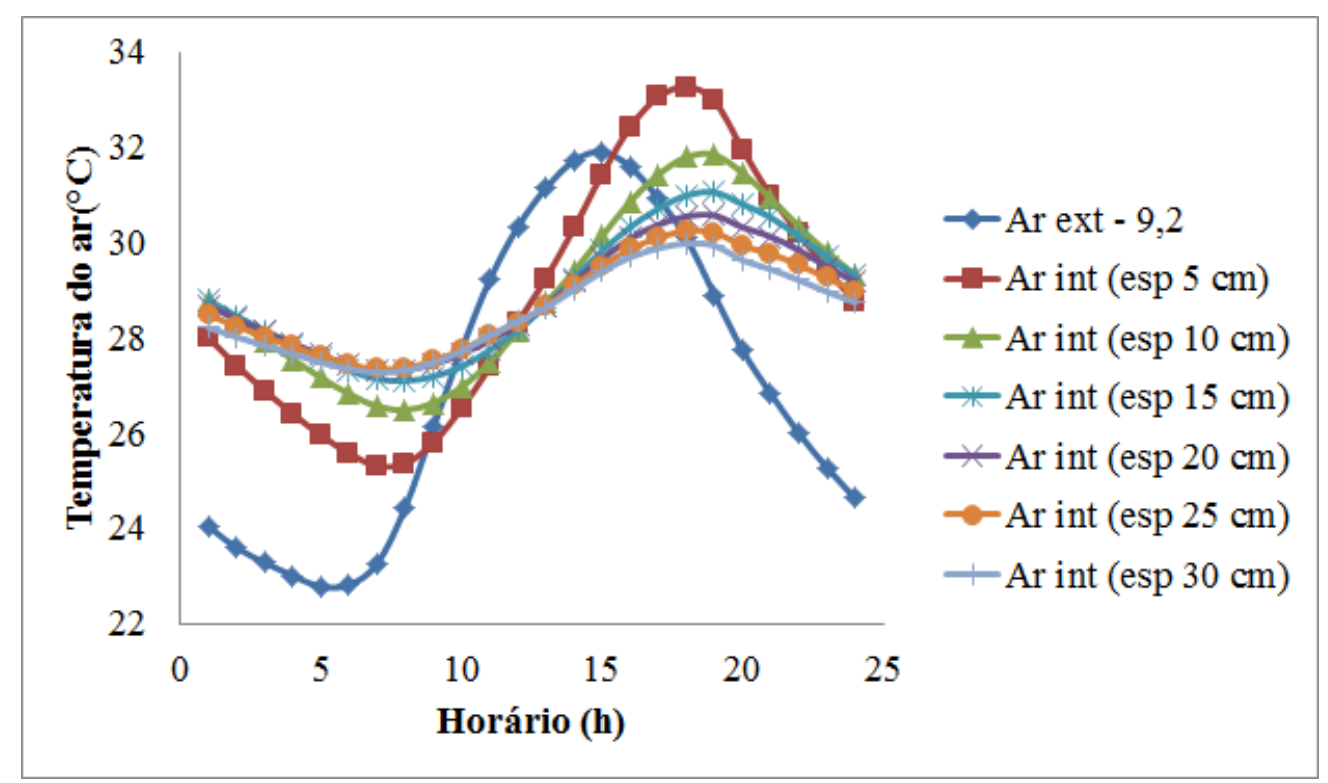




\subsection{Efeito da amplitude diária da temperatura do ar exterior na inércia térmica do ambiente}

À medida que se aumenta o valor da amplitude diária do ar exterior ocorre uma redução no valor do fator de amortecimento (Figuras 3 e 4). Este efeito é menos significativo para paredes com espessura acima de $15 \mathrm{~cm}$. Este comportamento térmico se repete em todas as condições analisadas.

Figura 3 - Fator de amortecimento com ambientes sem ventilação noturna, para as várias amplitudes diárias da temperatura do ar exterior.

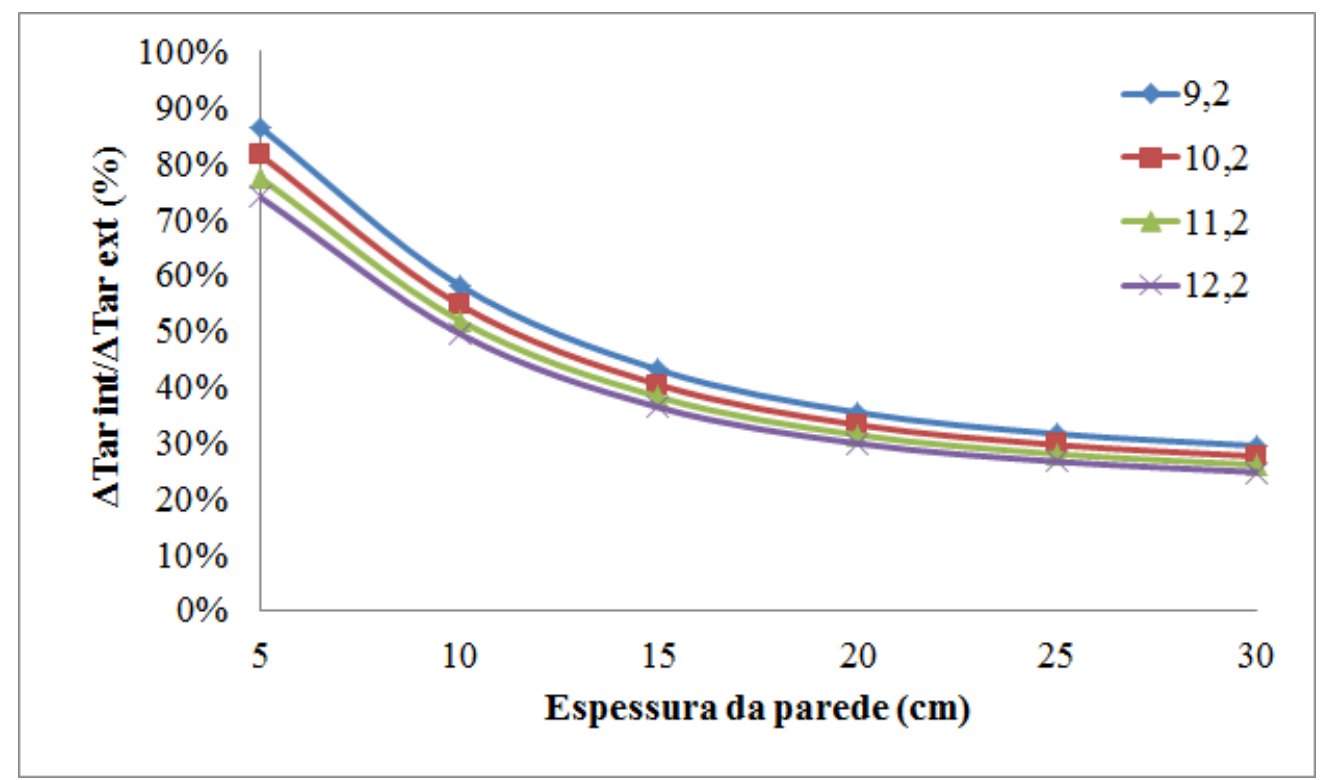

Figura 4 - Fator de amortecimento com ambientes com ventilação noturna, para as várias amplitudes diárias da temperatura do ar exterior.

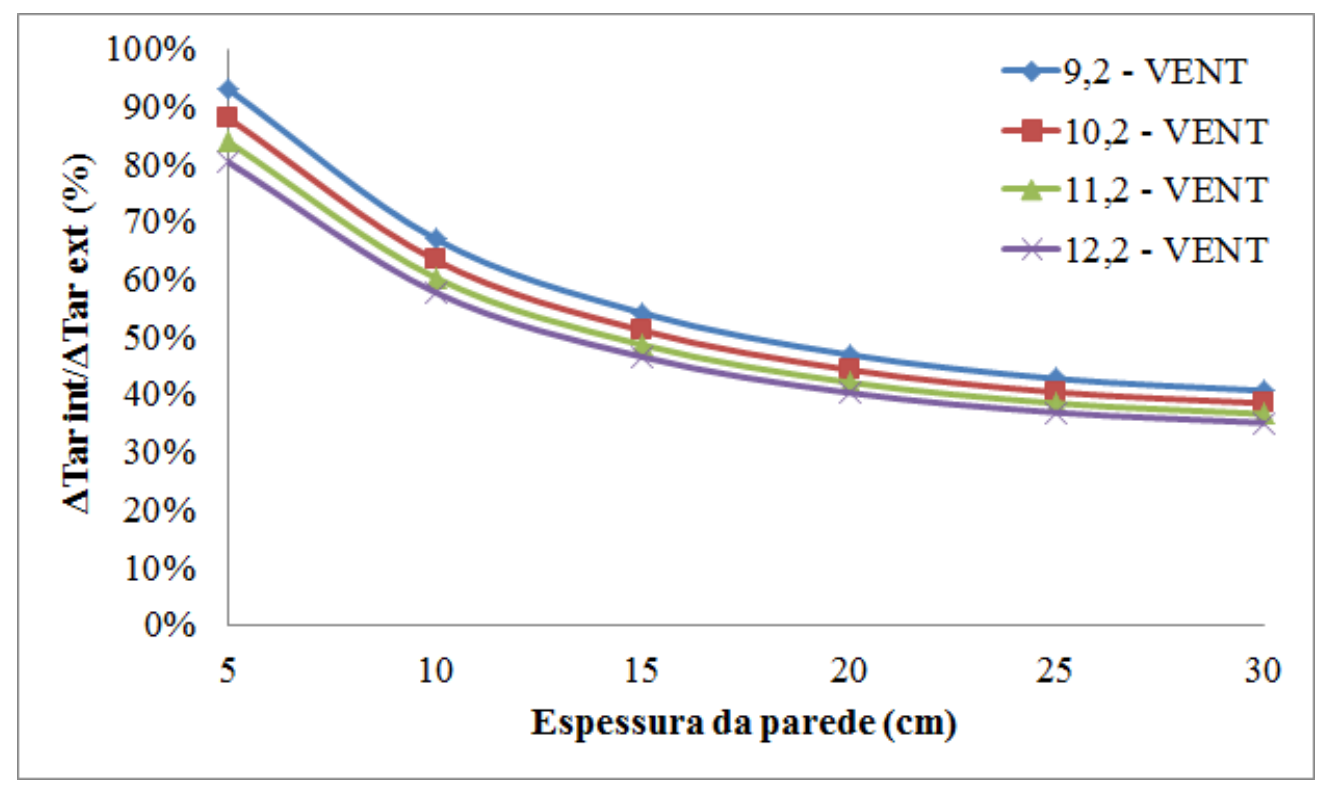

\subsection{Efeito da ventilação noturna na inércia térmica do ambiente}

Considerando-se a diferença entre os valores máximos da temperatura do ar nos ambientes com ou sem ventilação noturna, observa-se que a ventilação proporciona reduções pouco significativas nesta grandeza (Figuras 3, 4 e 5). 
Figura 5 - Diferença entre as temperaturas máximas do ar interior com e sem ventilação noturna, para as várias amplitudes diárias da temperatura do ar exterior e espessuras de parede.

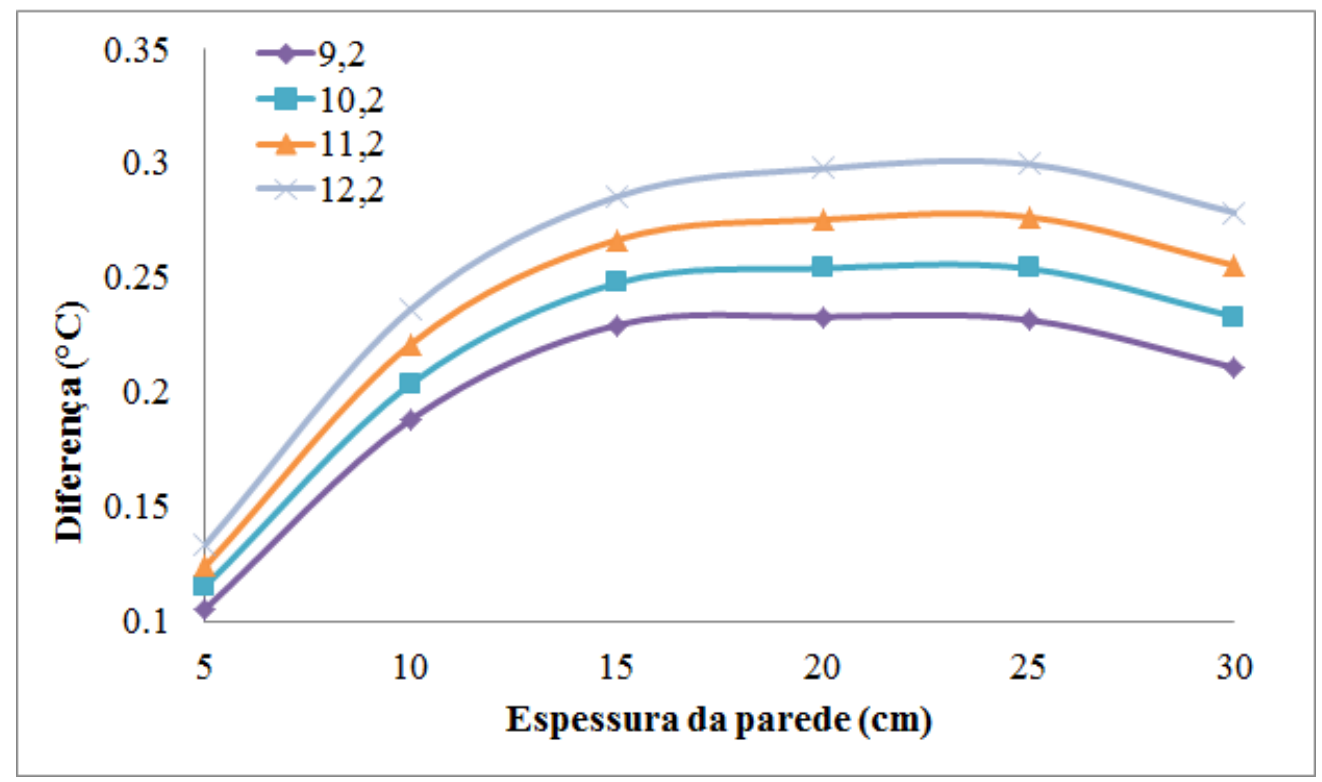

\section{CONCLUSÃO}

Foram feitas simulações computacionais do comportamento térmico de uma habitação para diferentes amplitudes diárias da temperatura do ar exterior, espessuras de paredes e com e sem ventilação noturna nos ambientes.

Observa-se que paredes com espessura de $15 \mathrm{~cm}$ de concreto convencional, que possuem capacidade térmica de $360 \mathrm{~kJ} / \mathrm{m}^{2} . \mathrm{K}$ e resistência térmica de $0,36 \mathrm{~m}^{2} . \mathrm{K} / \mathrm{W}$, proporcionam redução significativa na amplitude diária da temperatura do ar interior com fator de amortecimento da ordem de 40\%. Espessuras de paredes acima de $15 \mathrm{~cm}$ não apresentam reduções adicionais significativas.

$\mathrm{O}$ aumento da amplitude diária da temperatura do ar exterior de 9,2 a $12,2{ }^{\circ} \mathrm{C}$ proporciona redução no valor do fator de amortecimento para espessuras de paredes de até $15 \mathrm{~cm}$. Para espessuras maiores, a redução no fator de amortecimento é pouco significativa.

A ventilação do ambiente no período noturno não proporciona reduções significativas no valor da temperatura máxima do ar interior em quaisquer das condições analisadas.

Observa-se que estas conclusões são válidas para habitações com as características apresentadas neste artigo, expostas às condições climáticas da cidade de São Paulo.

\section{REFERÊNCIAS}

ABNT - Associaçao Brasileira de Normas Técnicas. 2005. NBR 15.220 - Desempenho Térmico de Edificações Parte 3: Zoneamento Bioclimático Brasileiro E Diretrizes Construtivas Para Habitações Unifamiliares de Interesse Social. Brasil.

ABNT - Associaçao Brasileira de Normas Técnicas. 2013. NBR 15.575-1 Edificações Habitacionais - Desempenho Parte 1: Requisitos Gerais. Brasil 
USDOE - UNITED STATES DEPARTMENT OF ENERGY. 2013. "Getting Started with EnergyPlus Basic Concepts Manual - Essential Information You Need about Running EnergyPlus."

CHAN, D. et al. Thermal evaluation of strategies for an adequate housing in arid zones and their impact on energy saving. International Conference of the International Building Performance Simulation Association. Kioto, Japão, 1999.

GREGORY, K. et al. Effect of thermal mass on the thermal performance of various Australian residential constructions systems. Energy and Buildings. 40, 2008. 459-465.

SÃO PAUlO (Cidade) Código de Obras e Edificações do Município de São Paulo; Lei $\mathbf{n}^{0}$ 11.228, de 25 de junho de 1992. Dispõe sobre as regras gerais e específicas a serem obedecidas no projeto, licenciamento, execução, manutenção e utilização de obras e edificações. São Paulo: Classe A, 1992.

VERBEKE, S. Thermal Inertia for small scale residential building. Building Performance Simulation in a Changing Environment. Viena: 2010. 